\title{
Once-daily, controlled-release tramadol and sustained-release diclofenac relieve chronic pain due to osteoarthritis: A randomized controlled trial
}

\author{
André D Beaulieu MD FRCPC ${ }^{1}$, Paul M Peloso MD MSc ${ }^{2}$, Boulos Haraoui MD ABIM FRCPC ${ }^{3}$, \\ William Bensen MD ABIM FRCPC ${ }^{4}$, Glen Thomson MD FRCPC ${ }^{5}$, John Wade MD FRCPC 6 , Patricia Quigley MSc ${ }^{7,8}$, \\ John Eisenhoffer $\mathrm{MD}^{8}$, Zoltan Harsanyi MBA${ }^{8}$, Andrew C Darke $\mathrm{PhD}^{8,9}$
}

\begin{abstract}
AD Beaulieu, PM Peloso, B Haraoui, et al. Once-daily, controlled-release tramadol and sustained-release diclofenac relieve chronic pain due to osteoarthritis: A randomized controlled trial. Pain Res Manage 2008;13(2):103-110.
\end{abstract}

OBJECTIVE: The present study was a randomized, parallel, doubleblind comparison between controlled-release (CR) tramadol and sustained-release (SR) diclofenac in patients with chronic pain due to osteoarthritis of the hips and/or knees.

METHODS: Patients with at least moderate pain intensity, and having received analgesics over the past three months, underwent a twoto seven-day washout of current analgesics before initiation of $200 \mathrm{mg}$ CR tramadol or $75 \mathrm{mg}$ SR diclofenac. During the eight-week study, patients returned to the clinic biweekly. CR tramadol doses were titrated to a maximum of $200 \mathrm{mg}, 300 \mathrm{mg}$ or $400 \mathrm{mg}$ per day. SR diclofenac doses were titrated to $75 \mathrm{mg}$ or $100 \mathrm{mg}$ once daily, or $75 \mathrm{mg}$ twice a day based on pain relief and the presence of side effects. For rescue analgesic, patients took acetaminophen as needed, up to $650 \mathrm{mg}$ three times a day.

RESULTS: Forty-five patients on CR tramadol and 52 patients on SR diclofenac were evaluable. Significant improvements from prestudy treatment were shown for visual analogue scale pain $(\mathrm{P}=0.0001)$, stiffness $(\mathrm{P}<0.0005)$ and physical function $(\mathrm{P}=0.0001)$ scores for both treatments. There were no significant differences between the two treatments in the Western Ontario and McMaster Universities subscales, overall pain, pain and sleep, or the clinical effectiveness evaluation. Overall incidence of adverse events was similar in both groups, with more opioid-related adverse events with CR tramadol, and two serious adverse events occurring with the use of SR diclofenac.

CONCLUSIONS: CR tramadol is as effective as SR diclofenac in the treatment of pain due to knee or hip osteoarthritis, with the potential for fewer of the serious side effects that characterize nonsteroidal anti-inflammatory drug administration.

Key Words: Chronic pain; Controlled-release; Diclofenac; NSAID; Osteoarthritis; Tramadol

$\mathrm{O}$ steoarthritis (OA) affects approximately $18 \%$ to $20 \%$ of the population aged 16 years and older in Canada (1). Pain is a major determinant of quality of life for patients with $\mathrm{OA}$. Inadequate treatment of pain can have many negative consequences, including decreased immune response and adverse psychological effects, such as anxiety, depression,
Le tramadol à libération contrôlée et le diclofénac à libération continue une fois par jour soulagent la douleur chronique causée par l'arthrose : Un essai aléatoire et contrôlé

OBJECTIF : La présente étude était une comparaison aléatoire et parallèle à double insu entre le tramadol à libération contrôlée (TLC) et le diclofénac à libération continue (DLC) chez les patients souffrant de douleur chronique causée par l'arthrose des hanches ou des genoux.

MÉTHODOLOGIE : Des patients présentant une intensité au moins modérée de la douleur et qui avaient pris des analgésiques au cours des trois mois précédents ont subi un sevrage de leurs analgésiques habituels pendant deux à sept jours avant d'entreprendre un traitement de $200 \mathrm{mg}$ de TLC ou de $75 \mathrm{~m}$ de DLC. Pendant l'étude de huit semaines, les patients sont allés à la clinique deux fois par semaine. Les doses de TLC ont été titrées à un maximum de 200 mg, 300 mg ou 400 mg par jour, tandis que celles de DLC l'étaient à $75 \mathrm{mg}$ ou $100 \mathrm{mg}$ une fois par jour, ou à $75 \mathrm{mg}$ deux fois par jour, d'après l'analgésie et la présence d'effets secondaires. Les patients prenaient de l'acétaminophène comme analgésique de rattrapage au besoin, jusqu'à concurrence de $650 \mathrm{mg}$ trois fois par jour.

RÉSULTATS : Quarante-cinq patients prenant du TLC et 52 patients prenant du DLC pouvaient être évalués. Avec les deux traitements et selon l'échelle visuelle analogique, les auteurs ont constaté des améliorations considérables par rapport au traitement d'avant l'étude pour ce qui est de la douleur $(\mathrm{P}=0,0001)$, de la raideur $(\mathrm{P}<0,0005)$ et de la fonction physique $(\mathrm{P}=0,0001)$. Ils n'ont toutefois remarqué aucune différence significative entre les deux traitements selon les sous-échelles hebdomadaires moyennes de l'université de Western Ontario et de l'université McMaster, de la douleur globale, de la douleur et du sommeil ou de l'évaluation d'efficacité clinique. L'incidence globale d'effets secondaires était similaire au sein des deux groupes, plus d'effets secondaires reliés aux opiacés s'étant produits au sein du groupe prenant du TLC et deux effets secondaires graves ayant découlé de l'utilisation du DLC.

CONCLUSIONS : Le TLC est aussi efficace que le DLC dans le traitement de la douleur causée par l'arthrose des genoux ou des hanches, mais il pourrait provoquer moins d'effets secondaires graves caractéristiques des anti-inflammatoires non stéroïdiens.

hopelessness, anger, hostility, poor interpersonal relations and suffering (2). The weakness, fatigue and stiffness as a result of progressive OA also contribute to decreased quality of life (2).

Typically, patients are treated with acetaminophen or nonsteroidal anti-inflammatory drugs (NSAIDs), such as cyclooxygenase 2 (COX-2)-specific inhibitors, naproxen, ibuprofen

${ }^{1}$ Centre de Rhumatologie St-Louis, Ste-Foy, Quebec; ${ }^{2}$ University of Iowa Hospitals and Clinics, Division of Rheumatology, Iowa City, Iowa,

USA; ${ }^{3}$ Rheumatic Diseases Unit, Centre hospitalier de l'Université de Montréal, Montreal, Quebec; ${ }^{4}$ McMaster University, Hamilton,

Ontario; ${ }^{5}$ University of Manitoba, Winnipeg, Manitoba; ${ }^{6}$ Laurel Medical Centre, Vancouver, British Columbia; ${ }^{7}$ Astellas Pharma US Inc,

Deerfield, Illinois, USA; ${ }^{8}$ Purdue Pharma, Pickering, Ontario; ${ }^{9}$ Applied Clinical Decisions, Pickering, Ontario

Correspondence: Dr John Eisenhoffer, Purdue Pharma, 575 Granite Court, Pickering, Ontario L1W 3W8. Telephone 800-387-5349,

fax905-420-2503, e-mail john.eisenhoffer@purdue.ca 
or diclofenac. Although acetaminophen has been shown to provide similar analgesic efficacy to naproxen in OA patients (3), it does not provide any anti-inflammatory effects, and there is a preference for NSAID treatment $(4,5)$. In a study of $\mathrm{OA}$ of the knee (6), an equal number of patients responded to acetaminophen and placebo, although mean change in pain intensity was greater for the acetaminophen group. In addition, while chronic therapeutic use of acetaminophen shows excellent tolerability, overdose has been associated with hepatic toxicity (7). Epidemiological studies have demonstrated a dose-dependent association between chronic renal failure and the long-term, daily ingestion of acetaminophen or acetylsalicylic acid (8). Patients receiving long-term NSAID therapy may experience severe gastrointestinal symptoms. NSAID-related ulceration and bleeding is estimated to result in up to 20,000 deaths each year in the United States (9). COX-2-specific inhibitors, such as celecoxib, may spare gastric mucosal prostaglandin synthesis, and consequently cause less gastrointestinal injury. However, a recent 12 -month study comparing celecoxib, ibuprofen and diclofenac found no difference in the incidence of complicated ulcers between the three treatments; the incidence of symptomatic ulcers was the same for celecoxib and diclofenac (10). Both COX-2-specific inhibitors and NSAIDs may affect fluid and electrolyte balance in some patients, resulting in fluid retention, edema and hypertension. There are controversies concerning the effects of COX-2-specific inhibitors on cardiovascular disease and bone fracture healing (11). A meta-analysis of randomized trials regarding COX-2 inhibitors found increased risk of cardiovascular events with rofecoxib and diclofenac (12). The most recent recommendations of the American Heart Association include tramadol, not NSAIDs or COX-2-specific inhibitors, as first-line therapy for musculoskeletal symptoms in patients with cardiovascular disease or risk factors (13). Thus, alternatives to NSAIDs and COX-2-specific inhibitors are needed.

Tramadol has an atypical pharmacological profile, involving both opioid and monoaminergic mechanisms. While it possesses analgesic effectiveness comparable with low doses of strong opioids, such as morphine, at therapeutic doses tramadol lacks typical opioid adverse effects, such as respiratory depression (14). The analgesic effects of tramadol are exerted by complementary mechanisms, including the activation of $\mu$-opioid receptors, and differential inhibition of serotonin and norepinephrine reuptake by the two isomers (15). The $(+)$ enantiomer is more potent than the (-) enantiomer in inhibiting serotonin reuptake (15). Conversely, the (-) enantiomer is more potent in inhibiting norepinephrine reuptake and increasing presynaptic release. The interaction between the two enantiomers may be synergistic (16). As a result of its serotonin-like activity, tramadol has been associated with an increased potential risk of seizures. Several large cohort and case-controlled studies with more than 9200 adults have provided some perspective on the risk of seizures in patients receiving tramadol (17-19). In general, fewer than $1 \%$ of tramadol users claimed to have had a presumed incident of seizure. Most cases were associated with cofactors, such as the use of above-maximum therapeutic doses, concomitant use of products associated with increased seizure risk, or a history of seizures or substance abuse. The risk of idiopathic seizures due to tramadol alone, with no risk factors present, was considered low.

Although very rare, there have been some case reports suggesting that serotonin toxicity may be induced in uncommon circumstances, such as the combination of high doses of tramadol with selective serotonin reuptake inhibitors and/or other products with serotonergic effects (20). Such combinations should therefore be used with caution, and concomitant use of monoamine oxidase inhibitors with tramadol is contraindicated.

Tramadol has been shown to be effective in the treatment of OA pain (16,21-23), and is generally well-tolerated. The American Pain Society recommends tramadol, alone or in combination with acetaminophen or NSAIDs, for the management of OA pain when NSAIDs alone produce inadequate pain relief (24). Unlike NSAIDs, tramadol does not irritate the gastrointestinal mucosa, or exacerbate hypertension or congestive heart failure, making it potentially useful for the elderly (2). For patients awaiting total joint replacement surgery, tramadol may be a good analgesic option if NSAIDs or COX-2-specific inhibitors are not tolerated, or provide suboptimal pain relief.

Tramadol has been extensively evaluated in the treatment of chronic pain, such as low back pain (25), cancer pain, painful diabetic neuropathy $(26,27)$, polyneuropathy (28) and fibromyalgia (29). Although tramadol may produce physical dependence during chronic use, little evidence of abuse has been found (30-34). Tolerance and dependence during longterm treatment is uncommon $(35,36)$ and withdrawal, when present, is not considered to be as severe as that produced by other opioids. The ability of tramadol to inhibit the neuronal uptake of monoamines in the same concentration range at which it binds to $\mu$-opioid receptors is distinct from typical opioids, and may explain its low potential for abuse in the treatment of chronic pain (26).

Compared with other centrally acting analgesics, tramadol has no clinically relevant cardiovascular effects (37) and insignificant effects on respiration (14). While $\mu$-opioid agonists have undesirable effects on gastrointestinal function, resulting in nausea, emesis, abdominal cramps and especially constipation, these effects are less severe with tramadol, and attenuate over time (38). Tramadol has only a minor delaying effect on colonic transit, and no effect on upper gastrointestinal transit or gut smooth muscle tone (38).

An immediate-release (IR) formulation of tramadol was compared with NSAIDs in two randomized, double-blind trials $(21,22)$ in patients with OA pain of at least moderate intensity. Although both treatments in these short trials produced equal pain relief, the incidence of side effects was greater with tramadol. An IR tramadol product containing acetaminophen was recently introduced into the Canadian market (39), although it has been restricted to short-term use for management of acute pain. A new controlled-release (CR) tramadol formulation has previously been shown to be comparable in efficacy with IR tramadol in the treatment of chronic OA pain (23). CR preparations not only provide an extended duration of action and reduced dosing frequency, but because of reduced fluctuations in plasma concentrations, they may provide a favourable efficacy and side effect profile, as well as improved compliance.

In a recently published double-blind crossover comparison of IR and CR tramadol in patients with chronic noncancer pain (40), CR tramadol was shown to have superior pain control (versus IR tramadol given as needed), full $24 \mathrm{~h}$ efficacy and higher patient-rated treatment efficacy (40). This same formulation was found to have superior pain control and functional 
improvements over placebo in a double-blind, randomized crossover trial (41). The present randomized, double blind, parallel study was designed to compare this CR tramadol formulation with sustained-release (SR) diclofenac in patients with OA pain of moderate or greater intensity.

\section{METHODS}

\section{Patients}

One hundred twenty-nine patients were enrolled into the study. Men and nonpregnant women between the ages of 35 and 75 years with primary OA were enrolled. Primary OA was defined by the presence of pain of at least moderate severity, stiffness, disability and bony crepitus of the hip and/or knee joint. Eligible patients had one hip or knee joint requiring use of NSAIDs, acetaminophen or opioid analgesics, on a scheduled or as-needed basis, for at least three months before the study. As well, they needed radiographic evidence of joint degeneration, from no more than six months before enrolment, in the medial and/or lateral tibiofemoral compartment, or in the hip, with a minimum severity of grade 2, as illustrated in the Standard Atlas of Radiographs of Arthritis (42). Grade 2 changes are defined by the presence of an osteophyte and joint space narrowing. Patients with more advanced radiographic grades were also eligible, as long as they were not awaiting surgery. Patients with intolerance to any opioid or NSAID, or a history of drug or alcohol abuse were excluded from the study. Patients with the following medical conditions were also excluded: renal or hepatic impairment, secondary OA, significant pain of alternate etiology, shortened gastrointestinal transit time, peptic ulcer disease, inflammatory disease of the gastrointestinal tract, a history of seizures or a recognized risk of seizures. Patients receiving corticosteroids, viscosupplementation, monoamine oxidase inhibitors, carbamazepine, quinidine, antidepressants, neuroleptics, cyclobenzaprine or promethazine were excluded from the study. Research ethics boards at the participating centres approved the protocol and informed consent, and each patient gave written informed consent before participating in the study.

\section{Medications}

Oral CR tramadol (Zytram XL, Purdue Pharma, Canada) in $200 \mathrm{mg}, 300 \mathrm{mg}$ and $400 \mathrm{mg}$ tablets or SR diclofenac (Voltaren SR, Novartis, Switzerland) in $75 \mathrm{mg}$ and $100 \mathrm{mg}$ tablets was administered once daily in the morning, or $75 \mathrm{mg}$ SR diclofenac was administered twice daily. All patients were randomly assigned an initial dose of either active CR tramadol $200 \mathrm{mg}$ and placebo SR diclofenac $75 \mathrm{mg}$ each morning, or active SR diclofenac $75 \mathrm{mg}$ and placebo CR tramadol $200 \mathrm{mg}$ each morning. The doses of active medication and placebo were titrated at weekly clinic visits (200 mg, $300 \mathrm{mg}$ or $400 \mathrm{mg}$ CR tramadol, or $75 \mathrm{mg}, 100 \mathrm{mg}$ or $150 \mathrm{mg}$ SR diclofenac) up to the maximum daily dose, unless adequate pain control was achieved or side effects prevented the dose from being titrated further. Study medication was prepackaged with an assigned randomization number, according to a computer-generated code, in blocks of four. Blinding was maintained using the double-dummy technique. Breakthrough pain was managed with $325 \mathrm{mg}$ to $650 \mathrm{mg}$ acetaminophen (Tylenol, McNeil Consumer Healthcare, Canada) every $4 \mathrm{~h}$ to $6 \mathrm{~h}$, as required.

\section{Study design}

The present study was a randomized, double-blind, parallelgroup comparison of the efficacy, safety and clinical effectiveness of CR tramadol and SR diclofenac over a six-week treatment period. Following the pretreatment visit (visit 1), all analgesics were withdrawn for a two- to seven-day washout period before randomization to active treatment.

On the evening before the first dose of active treatment, and every morning during the treatment evaluation, patients recorded their pain intensity in a diary using the pain subscale of the Western Ontario and McMaster Universities (WOMAC) OA index, and an overall pain intensity $100 \mathrm{~mm}$ visual analogue scale (VAS) (anchors: no pain, extreme pain) $(43,44)$. Patients were asked to rate their pain intensity experience while walking on a flat surface, going up or down stairs, at night while in bed, sitting or lying, and standing upright. The overall daily pain intensity was also assessed with a 100 mm VAS (anchors: no pain, extreme pain) by asking the patient, "What was your average pain over the past 24 hours?"

At visit 1 and each subsequent visit, patients completed the entire WOMAC questionnaire, including the pain, stiffness and physical function subscales, and provided an overall VAS score for pain intensity over the past two weeks. Severity of stiffness was assessed after first awakening in the morning, and after sitting, lying or resting later in the day (anchors: no stiffness, extreme stiffness). Physical function was assessed by asking the patients about their degree of difficulty with descending stairs, ascending stairs, rising from sitting, standing, bending to the floor, walking on flat surfaces, getting in and out of a car, going shopping, putting on socks or stockings, rising from bed, taking off socks or stockings, lying in bed, getting in and out of the bath, sitting, getting off and on the toilet, heavy domestic duties and light domestic duties (anchors: no difficulty, extreme difficulty).

The impact of pain on quantity and quality of sleep was assessed at visit 1 and each clinic visit using the Pain and Sleep Questionnaire, which consists of eight items related to the impact of pain on sleep. Seven items were rated on a $100 \mathrm{~mm}$ VAS (anchors: never to always), and one item was based on the number of hours of sleep. The scores for items 1 through 5 of the Pain and Sleep Questionnaire ('trouble falling asleep due to pain', 'needed pain medication to sleep', 'needed sleeping medication to sleep', 'awakened by pain at night' and 'awakened by pain in the morning') were summed to determine a composite score.

At the completion of the study, the patient and investigator each provided a global assessment of clinical effectiveness, using a seven-point categorical scale (markedly improved, moderately improved, slightly improved, no change, slightly worse, moderately worse, markedly worse). The propensity for abuse was assessed by completion of the Drug Liking Index, a nine-point scale ( 1 = 'I dislike the drug effect very much' and $9=$ 'I like the drug effect very much').

Adverse events spontaneously reported by patients and adverse events observed by the investigator were recorded at each visit.

\section{Data analysis}

The primary measures of efficacy were the daily overall pain intensity VAS score and the daily WOMAC VAS pain subscale score. Because the dose was titrated upwards during the six-week treatment period, efficacy data from weeks 4 to 6 served as the primary basis for comparing the two treatments. All randomly assigned patients were included in the intent-totreat (ITT) population, with the exception of one patient who 


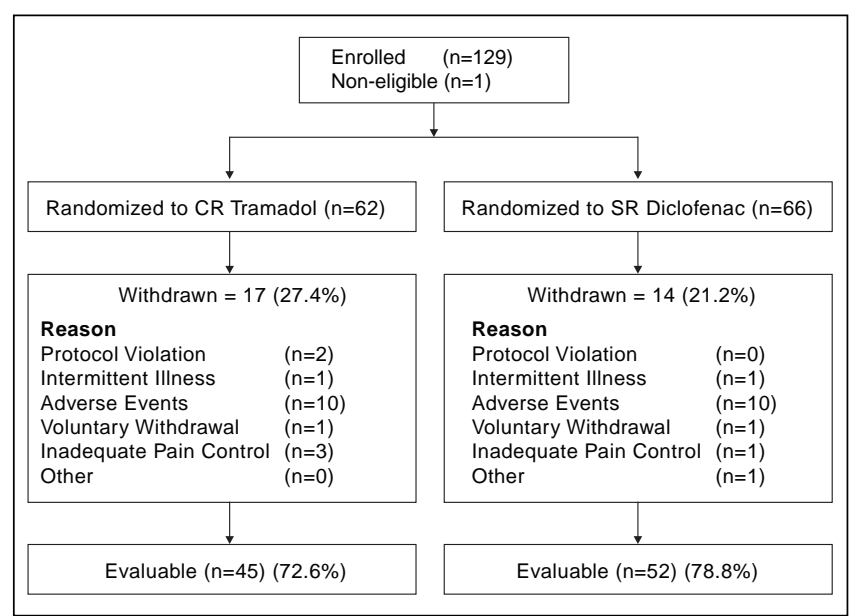

Figure 1) Patient disposition. CR Controlled-release; SR Sustainedrelease

\section{TABLE 1}

Joints affected by osteoarthritis

\begin{tabular}{lcc}
\hline & \multicolumn{2}{c}{ Number of patients, $\mathbf{n}(\%)$} \\
\cline { 2 - 3 } Joint & CR tramadol & SR diclofenac \\
\hline Left knee & $37(82)$ & $40(77)$ \\
Right knee & $38(84)$ & $44(85)$ \\
Left hip & $12(37)$ & $20(38)$ \\
Right hip & $14(31)$ & $24(46)$ \\
Other* & $14(33)$ & $18(35)$
\end{tabular}

The mean number of joints involved was $2.6 \pm 1.0$ and $2.8 \pm 1.3$ for the CR tramadol and $S R$ diclofenac groups, respectively $(P=0.6261)$. ${ }^{*}$ Other joints included backs, hands, feet, fingers, toes, shoulders, wrists, ankles and necks. CR Controlled-release; SR Sustained-release

did not meet the eligibility criteria. All patients who completed the study were included in the per protocol population, with the exception of one patient with a protocol violation. Safety data are presented using the ITT population and efficacy data are presented using the per protocol population.

The characteristics of the two treatment groups were compared for both demographic and efficacy variables. Change from prestudy treatment was tested using the paired $t$ test, and 95\% confidence limits were calculated for the difference among treatments in change scores. Categorical outcome measures were analyzed using Pearson's $\chi^{2}$ to determine differences between groups, and McNemar's $\chi^{2}$ to determine differences between treatment visits among patients. Analysis of covariance, using visit 1 as a covariate, was used to compare treatment effects for continuous variables. Compliance data and acetaminophen use were analyzed by repeated measures ANOVA, comparing treatment groups at treatment weeks 2, 4 and 6.

The sample size was estimated based on type 1 and type 2 error rates of $\alpha=0.05$ (two-tailed) and $\beta=0.20$ for a parallel group study, assuming a $15 \mathrm{~mm}$ difference in pain intensity score to be clinically meaningful, as proposed by Bellamy et al (45). All data are reported as mean \pm SD.

\section{RESULTS}

One hundred twenty-nine patients were enrolled. However, one patient was excluded from all analyses due to lack of evidence of OA, leaving 128 patients in the ITT population.

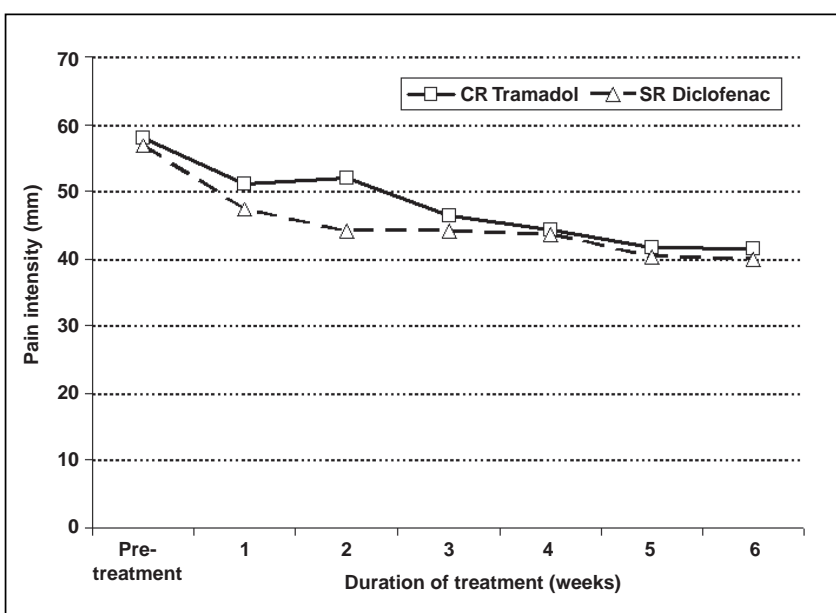

Figure 2) Pain intensity ( $100 \mathrm{~mm}$ visual analogue scale) by week during controlled-release (CR) tramadol and sustained-release (SR) diclofenac treatment

Sixty-two patients were randomly assigned to the CR tramadol group (42 women and 20 men) and 66 patients were randomly assigned to the SR diclofenac group (44 women and 22 men). Ninety-seven patients were evaluated for efficacy; 45 in the CR tramadol group (mean age $59.4 \pm 9.5$ years) and 52 in the SR diclofenac group (mean age $64.7 \pm 6.9$ years). The reasons for patient withdrawal were similar in both groups and are shown in Figure 1.

The mean duration of $\mathrm{OA}$ was $9.3 \pm 8.4$ years and $12.0 \pm 10.0$ years for the $\mathrm{CR}$ tramadol and SR diclofenac groups, respectively $(\mathrm{P}=0.3576)$. A description of the joints involved is shown in Table 1. The mean number of joints involved was $2.6 \pm 1.0$ and $2.8 \pm 1.3$ for the CR tramadol and SR diclofenac groups, respectively $(\mathrm{P}=0.6261)$. Ninety-four per cent of patients in the CR tramadol group, and $88 \%$ of patients in the SR diclofenac group had an OA grade of 2 or 3 for their worst joint.

During the last two weeks of treatment (visits 4 and 5), the mean daily dose of CR tramadol (370.2 $\pm 51.9 \mathrm{mg}$ at each visit) and SR diclofenac $(142.6 \pm 23.8 \mathrm{mg}$ and $141 \pm 23.6 \mathrm{mg}$ for visits 4 and 5 , respectively) remained stable. The maximum daily dose of CR tramadol and SR diclofenac was attained by $73 \%$ and $83 \%$ of patients, respectively. Patients could use up to six $325 \mathrm{mg}$ tablets of acetaminophen per day for unrelieved pain. The mean weekly numbers of rescue tablets consumed for week 6 were 1.6 \pm 2.1 and $1.7 \pm 2.0$ for CR tramadol and SR diclofenac, respectively. There was no significant difference in the amount of rescue medication consumed between the treatment groups or between the weeks of treatment for either group.

There was no significant difference between the overall VAS pain scores and the WOMAC pain subscale averaged weekly for the two treatments. However, pain scores decreased significantly from pretreatment assessed at visit 1 for both treatments, starting at week 1 (Figure 2 and Figure 3 ). The mean pretreatment scores for the WOMAC pain subscale were $257.1 \pm 98.7$ and $257.6 \pm 116.4$ for CR tramadol and SR diclofenac, respectively. Mean change from visit 1 to the last week of treatment (week 6) for the WOMAC pain subscale was 73.2 $\pm 99.9(\mathrm{P}=0.0001)$ for $\mathrm{CR}$ tramadol and $80.2 \pm 108.1$ $(\mathrm{P}=0.0001)$ for $\mathrm{SR}$ diclofenac. Mean change from visit 1 for the overall VAS pain score was $17.3 \pm 22.6(\mathrm{P}=0.0001)$ for $\mathrm{CR}$ tramadol, and $16.4 \pm 24.4(\mathrm{P}=0.0001)$ for $\mathrm{SR}$ diclofenac. 


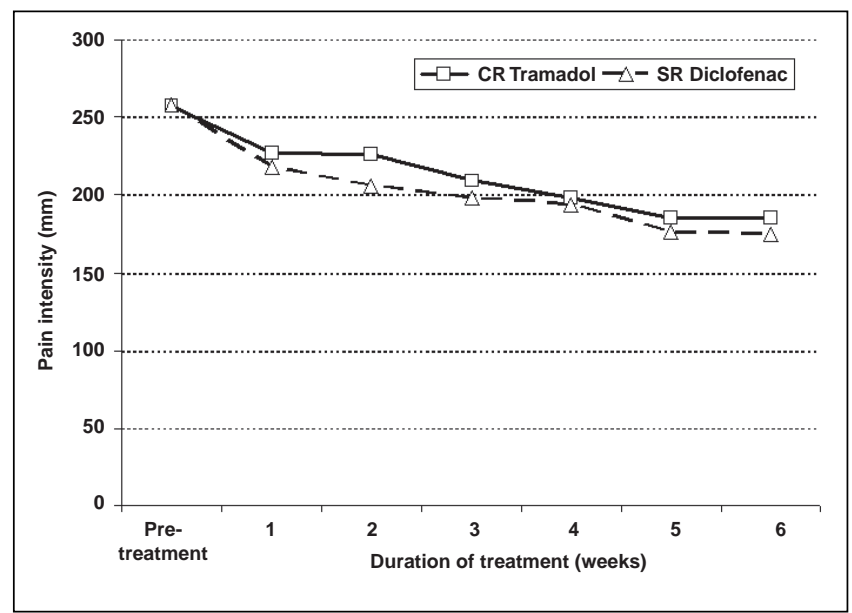

Figure 3) Western Ontario and McMaster Universities pain subscale by week during controlled-release (CR) tramadol and sustained-release (SR) diclofenac treatment

\section{TABLE 2}

Western Ontario and McMaster Universities physical function and stiffness subscales completed at clinic visits

\begin{tabular}{|c|c|c|c|c|}
\hline \multirow[b]{2}{*}{$\begin{array}{l}\text { Time } \\
\text { (weeks) }\end{array}$} & \multicolumn{2}{|c|}{ Physical function } & \multicolumn{2}{|c|}{ Stiffness } \\
\hline & $\begin{array}{c}\mathrm{CR} \\
\text { tramadol }\end{array}$ & $\begin{array}{c}\text { SR } \\
\text { diclofenac }\end{array}$ & $\begin{array}{c}\mathrm{CR} \\
\text { tramadol }\end{array}$ & $\begin{array}{c}\text { SR } \\
\text { diclofenac }\end{array}$ \\
\hline 0 (visit 1) & $890.8 \pm 313.0$ & $854.5 \pm 392.1$ & $124.0 \pm 48.0$ & $115.8 \pm 50.5$ \\
\hline 2 & $793 \pm 427.8^{*}$ & $696.3 \pm 434.7^{*}$ & $107.2 \pm 52.1^{*}$ & $86.4 \pm 51.3^{*}$ \\
\hline 4 & $685 \pm 404.6^{*}$ & $651.7 \pm 449.8^{*}$ & $92.2 \pm 47.4^{*}$ & $82.4 \pm 57.9^{*}$ \\
\hline 6 & $633.9 \pm 406.7^{*}$ & $607.1 \pm 456.2^{*}$ & $89.7 \pm 52.4^{*}$ & $79 \pm 56.2^{*}$ \\
\hline
\end{tabular}

${ }^{*} P<0.05$ for change from baseline. CR Controlled-release; SR Sustainedrelease

The mean difference between treatments, in change from prestudy treatment, for overall VAS pain intensity was 0.39 , with an upper 95\% confidence level of 8.5. For the WOMAC pain subscale (standardized to $100 \mathrm{~mm}$ ), the corresponding mean difference was -1.4 , with an upper $95 \%$ confidence level of 5.8. For both measures, the upper $95 \%$ confidence level was below $10 \mathrm{~mm}$.

Both treatment groups improved significantly from pretreatment for physical functioning (mean change of $257.0 \pm 354.4$ for $\mathrm{CR}$ tramadol, $\mathrm{P}=0.0005$, and $247.4 \pm 379.5$ for SR diclofenac, $\mathrm{P}=0.0001$ ) and stiffness (mean change of 34.3 \pm 61.4 for CR tramadol, $\mathrm{P}=0.0005$, and $36.8 \pm 57.4$ for $\mathrm{SR}$ diclofenac, $\mathrm{P}=0.0001$ ) as measured by the WOMAC subscales completed at the first clinic visit and at the end of the present study. There was no significant difference between the two treatment groups (Table 2).

Pain and Sleep Index scores for the two treatment groups were similar at visit 1 and at the end of treatment (Table 3). For each of the categories in the Pain and Sleep Index, the mean response decreased compared with visit 1 , indicating improved sleep. There was no statistically significant difference between the treatment groups at visit 1 or visit 5 . No significant difference was found between the treatment groups for the 'pain and sleep' score and the 'quality of sleep' score, but a significant result was found for the covariate, indicating a significant change from prestudy treatment at the end of the present study.

Patients were asked to rate how much they liked or disliked the nonanalgesic effects of the drug at the end of the study.
TABLE 3

Impact of pain on sleep at baseline and visits 4 and 5 of each treatment

\begin{tabular}{lccccc}
\hline & \multicolumn{2}{c}{ CR tramadol } & & \multicolumn{2}{c}{ SR diclofenac } \\
\cline { 2 - 3 } \cline { 5 - 6 } Question*t & Baseline & Visits 4 and 5 & & Baseline & Visits 4 and 5 \\
\hline $\begin{array}{c}\text { Hours of sleep } \\
\text { Quality of sleep }\end{array}$ & $6.7 \pm 1.5$ & $6.9 \pm 1.4$ & & $6.3 \pm 1.5$ & $6.4 \pm 1.4$ \\
$\begin{array}{c}\text { Trouble falling } \\
\text { asleep }\end{array}$ & $35.9 \pm 30.9$ & $21.0 \pm 23.3$ & & $43.8 \pm 32.5$ & $32.0 \pm 34.8$ \\
$\begin{array}{c}\text { Need pain } \\
\text { meds to sleep }\end{array}$ & $39.5 \pm 35.3$ & $22.4 \pm 31.0$ & & $43.1 \pm 39.3$ & $27.2 \pm 35.1$ \\
$\begin{array}{c}\text { Need sleeping } \\
\text { meds to sleep }\end{array}$ & $17.5 \pm 28.3$ & $10.5 \pm 23.8$ & & $17.6 \pm 29.1$ & $15.0 \pm 27.6$ \\
$\begin{array}{c}\text { Awakened by } \\
\text { pain at night }\end{array}$ & $40.9 \pm 32.5$ & $27.8 \pm 31.5$ & & $44.0 \pm 32.3$ & $32.0 \pm 32.2$ \\
$\begin{array}{c}\text { Awakened by } \\
\text { pain in morning }\end{array}$ & $35.0 \pm 31.6$ & $25.1 \pm 29.0$ & & $39.6 \pm 33.9$ & $27.3 \pm 29.5$ \\
$\begin{array}{c}\text { Awakened by } \\
\text { partner }\end{array}$ & $20.5 \pm 24.2$ & $20.7 \pm 28.0$ & $28.4 \pm 32.5$ & $14.8 \pm 23.7$ \\
$\begin{array}{c}\text { Overall pain } \\
\text { and sleep }\end{array}$ & $180.0 \pm 113.0$ & $117.3 \pm 120.7$ & $203.0 \pm 139.3$ & $140.1 \pm 143.6$ \\
\hline
\end{tabular}

*All scales are $100 \mathrm{~mm}$ visual analogue scales, except for hours of sleep and the overall pain and sleep (composite) score; ${ }^{+}$Lower scores indicate a lower impact of pain on sleep, except for 'hours of sleep' and 'quality of sleep', where higher scores are better. CR Controlled-release; Meds Medication; SR Sustained-release

There was no significant difference between treatment groups in the scores for the Drug Liking Index. Of the 45 patients in the CR tramadol group, six disliked the drug effect, 22 neither liked nor disliked the drug effect and 17 liked the drug effect. Of the 52 patients in the SR diclofenac group, two disliked the drug effect, 31 neither liked nor disliked the drug effect and 19 liked the drug effect. Therefore, the majority of the patients neither liked nor disliked the drug effect ( $49 \%$ for CR tramadol and 60\% for SR diclofenac, $\mathrm{P}=0.8000$ ).

For global effectiveness, $67 \%$ and $54 \%$ of the evaluated patients reported moderate to marked improvement with $\mathrm{CR}$ tramadol and SR diclofenac, respectively $(\mathrm{P}=0.6590)$. Investigators also indicated patients' pain improved moderately or markedly with CR tramadol (49\%) and SR diclofenac $(54 \%) \quad(P=0.4290)$. No significant difference was found between the treatments for global effectiveness.

The overall incidence of adverse events related to the study drug was similar for both treatments, with 78\% of CR tramadol patients reporting 165 adverse events and 59\% of SR diclofenac patients reporting 101 adverse events. Early discontinuations from the study due to adverse events occurred in 16\% and $15 \%$ of patients in the CR tramadol and SR diclofenac groups, respectively. The most commonly reported adverse events related to the study medication for both groups are given in Table 4. Ten patients from each treatment group withdrew due to similar adverse events, such as gastrointestinal upset and dizziness.

As patients in the present study were titrated to the most effective dose over time, adverse events were examined posthoc by the final dose of CR tramadol. Patients were subdivided into those who were stabilized on $400 \mathrm{mg}(\mathrm{n}=34)$, $300 \mathrm{mg}$ to $350 \mathrm{mg}(\mathrm{n}=17)$ and $200 \mathrm{mg}$ to $250 \mathrm{mg}(\mathrm{n}=10)$ of CR tramadol. One patient's dose was unknown due to noncompliance. While constipation was stable across all dose ranges (20.0\%, 23.5\% and $20.6 \%$ for $200 \mathrm{mg}$ to $250 \mathrm{mg}, 300 \mathrm{mg}$ to $350 \mathrm{mg}$ and $400 \mathrm{mg}$, respectively), there were declines in other 
TABLE 4

Incidence of most common adverse events related to study medication

\begin{tabular}{lcc}
\hline & \multicolumn{2}{c}{ Incidence, $\mathbf{n}(\%)$} \\
\cline { 2 - 3 } Event & CR tramadol & SR diclofenac \\
\hline Dizziness & $15(24.2)$ & $12(18.2)$ \\
Nausea & $15(24.2)$ & $7(10.6)$ \\
Constipation & $13(21.0)$ & $10(15.2)$ \\
Somnolence & $11(17.7)$ & $5(8.1)$ \\
Vomiting & $9(14.5)$ & $3(4.5)$ \\
Headache & $7(11.3)$ & $1(1.5)$ \\
Sweating & $9(14.5)$ & $0(0)$ \\
Abdominal pain & $2(3.2)$ & $6(9.1)$ \\
\hline
\end{tabular}

CR Controlled-release; SR Sustained-release

adverse events, such as dizziness $(60.0 \%, 41.2 \%$ and $11.8 \%$ for $200 \mathrm{mg}$ to $250 \mathrm{mg}, 300 \mathrm{mg}$ to $350 \mathrm{mg}$ and $400 \mathrm{mg}$, respectively) and nausea $(30.0 \%, 41.2 \%$ and $17.6 \%$ for $200 \mathrm{mg}$ to $250 \mathrm{mg}$, $300 \mathrm{mg}$ to $350 \mathrm{mg}$ and $400 \mathrm{mg}$, respectively) for the three dose ranges.

Two patients treated with SR diclofenac experienced serious adverse events; one patient was hospitalized for gastrointestinal bleeding after 45 days of treatment and the other patient was hospitalized for severe pancreatitis after 14 days of treatment. Both of these events were judged to be related to $\mathrm{SR}$ diclofenac. There were no serious adverse events in patients treated with CR tramadol.

\section{DISCUSSION}

The results of the present trial demonstrated that CR tramadol is as effective as SR diclofenac in the treatment of pain due to $\mathrm{OA}$ of the hip and/or knee. Patients in both groups reported improved pain relief at the end of the treatment period, compared with prestudy treatment. Furthermore, patients reported improvements in sleep quality and physical function, which are important determinants of quality of life in patients with chronic musculoskeletal disease. Because lack of sleep can exacerbate pain, improvement of sleep is an important goal of pain management (46). Patients were titrated to stable and effective doses of CR tramadol and SR diclofenac within four to six weeks of initiation, showing statistically significant improvements in pain control and physical functioning.

In a recent meta-analysis of randomized controlled trials (47), it was found that treatment of OA with tramadol led to decreases in pain intensity and improvements in function. In the discussion, the authors concluded that the maximum expected decrease in pain intensity with tramadol treatment was $12.5 \mathrm{~mm}$ on a $100 \mathrm{~mm}$ VAS scale. The authors rated this level of pain relief as similar to that of acetaminophen, and inferior to that of NSAIDs. In a comparison of CR tramadol with placebo, using the same methodology as the present study, VAS reductions of $5.7 \mathrm{~mm}$ were observed for the placebo arm (48). In the present study, however, decreases of $17.4 \mathrm{~mm}$ and $16.4 \mathrm{~mm}$ were seen for CR tramadol and SR diclofenac, respectively, indicating that properly dosed tramadol can be equally efficacious as an NSAID product.

In a titration-to-effect crossover study by Beaulieu et al (40), once-daily dosing of CR tramadol was compared with IR tramadol given as needed. Interestingly, the patients who selfadministered IR tramadol as needed considerably underdosed their medication compared with the patients taking scheduled CR tramadol, resulting in poorer pain control. In the present study, scheduled, once-daily CR tramadol and SR diclofenac were used to a maximum dose of $400 \mathrm{mg} /$ day and $150 \mathrm{mg} /$ day, respectively, to differentiate from the Pavelka study (49). This difference in the dosing schedule was associated with a much higher average total daily dose of CR tramadol, compared with the average total daily dose of IR tramadol relative to the Beaulieu et al study (370.2 mg versus $164.8 \mathrm{mg}$ for tramadol) (40). In an earlier study by Pavelka et al (49), IR tramadol was compared with IR diclofenac in OA patients. Both medications were given as needed, to a maximum dose of $300 \mathrm{mg} /$ day for tramadol and $150 \mathrm{mg} /$ day for diclofenac. Correspondingly, patients experienced greater functional improvement in the overall WOMAC pain, stiffness and function scores in the present study, compared with the study of Pavelka et al $(26.8 \%$ versus $19.2 \%$ with tramadol, and $27.5 \%$ versus $24.8 \%$ with diclofenac) (49). In a recent comparison with CR tramadol, placebo response on the WOMAC function score was $19.2 \%$ (48). The incidence of adverse events was also lower in the study of Pavelka et al (20\% and 3\% of patients during tramadol and diclofenac treatment, respectively, compared with $78 \%$ and $65 \%$ in the present study) (49), which is consistent with the lower doses used when analgesics were prescribed on an as-needed basis.

Adverse events usually occur at the beginning of tramadol therapy and diminish with continued treatment (50). High initiation doses and rapid titration of IR tramadol were reported to lead to intolerable adverse events and discontinuation of treatment in more than $30 \%$ of patients, possibly as many as 50\% (51,52). In the present study, CR tramadol titrations were made at weekly intervals from a starting dose of $150 \mathrm{mg}$ daily. This resulted in good tolerability, with $16 \%$ of discontinuations due to adverse events. There were no indications of an increase in adverse events at higher doses of tramadol. This was similar to the SR diclofenac group, in which $15 \%$ of withdrawals were due to adverse events. A majority of patients, on either product, attained the maximum daily dose permitted: $400 \mathrm{mg}$ of CR tramadol and $150 \mathrm{mg}$ of SR diclofenac.

Previous studies have shown that tramadol is as effective as NSAIDs (21,49), and more effective than dextropropoxyphene (53) in the treatment of chronic OA pain. However, patients receiving long-term NSAID therapy risk severe gastrointestinal symptoms, including ulceration and bleeding. In most patients, and especially high-risk groups such as elderly patients, concurrent cytoprotective agents are recommended, increasing the cost of treatment (54). The results of a large meta-analysis (9) of published and unpublished data supported the association between NSAID use and serious upper gastrointestinal complications, and in another metaanalysis (12), diclofenac had a relative risk of serious cardiovascular events of 1.40 (95\% CI 1.16 to 1.70$)$. In the present study, one patient in the diclofenac treatment group experienced gastrointestinal bleeding and another patient experienced pancreatitis. For OA patients exhibiting gastrointestinal intolerance of NSAIDs, a trial course of tramadol would represent an alternative therapy without similar risks for gastrointestinal toxicities. There were no serious adverse events experienced by patients during treatment with CR tramadol. This adverse event profile suggests that CR tramadol, and not acetaminophen-codeine combination products, is the suitable 
alternative for patients intolerant of, or unsuitable for, NSAID therapy.

The three-step ladder, proposed for cancer pain relief by the World Health Organization (WHO), is now widely used for all types of pain. Step 1 includes nonopioid analgesics, step 2, weak opioids, and step 3, strong opioids. It was suggested that tramadol should be retained in step 2 with codeine (55), the prodrug for morphine that is commonly used in modest doses for the treatment of OA pain, usually in combination with either acetaminophen or acetylsalicylic acid. Stronger opioids, such as CR oxycodone, are also effective in the treatment of moderate to severe pain due to OA $(56-58)$. They may be reserved for OA pain refractory to other treatments, as is consistent with the American Pain Society and the WHO analgesic ladder (34).

The present study showed a trend toward slightly higher incidences of adverse events with CR tramadol, compared with SR diclofenac (52 and 49 patients, respectively), although there was no significant difference in the number of patients withdrawing due to adverse events. More patients in the CR tramadol treatment group reported nausea than patients in the SR diclofenac treatment group (15 and seven patients, respectively), whereas more patients in the SR diclofenac group reported abdominal pain than in the CR tramadol group (six and two patients, respectively).

Although tramadol exerts its analgesic effect through a weak binding affinity for the $\mu$-opioid receptor, it also binds weakly to the serotonin presynaptic receptor, causing it to act

\section{REFERENCES}

1. Badley EM. The effect of osteoarthritis on disability and health care use in Canada. J Rheumatol Suppl 1995;43:19-22.

2. Roth SH, Reder RF. The role of opioids in the treatment of osteoarthritis. Resid Staff Physician 1998;44:31-6.

3. Williams HJ, Ward JR, Egger MJ, et al. Comparison of naproxen and acetaminophen in a two-year study of treatment of osteoarthritis of the knee. Arthritis Rheum 1993;36:1196-206.

4. Wolfe F, Zhao S, Lane N. Preference for nonsteroidal antiinflammatory drugs over acetaminophen by rheumatic disease patients: A survey of 1,799 patients with osteoarthritis, rheumatoid arthritis, and fibromyalgia. Arthritis Rheum 2000;43:378-85.

5. Pincus T, Koch G, Lei H, et al. Patient Preference for Placebo, Acetaminophen (paracetamol) or Celecoxib Efficacy Studies (PACES): Two randomised, double blind, placebo controlled, crossover clinical trials in patients with knee or hip osteoarthritis. Ann Rheum Dis 2004;63:931-9.

6. Miceli-Richard C, Le Bars M, Schmidely N, Dougados M. Paracetamol in osteoarthritis of the knee. Ann Rheum Dis 2004;63:923-30.

7. Graham GG, Scott KF, Day RO. Tolerability of paracetamol. Drug Saf 2005;28:227-40.

8. Fored CM, Ejerblad E, Lindblad P, et al. Acetaminophen, aspirin, and chronic renal failure. N Engl J Med 2001;345:1801-8.

9. Ofman JJ, MacLean CH, Straus WL, et al. A meta-analysis of severe upper gastrointestinal complications of nonsteroidal antiinflammatory drugs. J Rheumatol 2002;29:804-12

10. Important safety information for patients taking Celebrex (celecoxib). <http://www.hc-sc.gc.ca/ahc-asc/media/advisoriesavis/_2002/2002_40_e.html > (Version current at March 26, 2008).

11. Simon AM, Manigrasso MB, O'Connor JP. Cyclo-oxygenase 2 function is essential for bone fracture healing. J Bone Miner Res 2002;17:963-76.

12. McGettigan P, Henry D. Cardiovascular risk and inhibition of cyclo-oxygenase: A systematic review of the observational studies of selective and nonselective inhibitors of cyclo-oxygenase 2. JAMA 2006;296:1633-44. as an atypical opioid analgesic. Consistent with this atypical profile, and as recently summarized by WHO, no significant respiratory or cardiac side effects have been associated with tramadol when the drug is given at the recommended oral doses $(14,31,34)$. Tolerance, dependence, diversion and abuse also appear to be lower with tramadol than other opioids $(31,34)$. In the present study, assessment of patient approval of tramadol was not significantly different from that of diclofenac, which is consistent with the results of two postmarketing surveillance studies that confirm the low abuse potential of tramadol. In an American postmarketing surveillance study (32), the rate of abuse was low, with only two cases per 100,000 patients in the first 18 months of availability, and a decline to one case per 100,000 patients in the succeeding 18 month period. Most of the cases occurred in individuals with a history of substance abuse (32). In a second study of health care professionals (33), the incidence of tramadol abuse or dependence was only 6.9 per 1000 patients per year.

\section{CONCLUSION}

CR tramadol, a once-daily formulation marketed as Zytram $\mathrm{XL}$, is as effective as SR diclofenac in the treatment of pain due to knee or hip OA, with the potential for fewer of the serious side effects that characterize NSAID administration.

SUPPORT: This study was supported by a research grant from Purdue Pharma, Canada.
13. Antman EM, Bennett JS, Daugherty A, Furberg C, Roberts H, Taubert KA. Use of nonsteroidal anti-inflammatory drugs: An update for clinicians: A scientific statement from the American Heart Association. Circulation 2007;115:1634-42.

14. Houmes RJ, Voets MA, Verkaaik A, Erdmann W, Lachmann B. Efficacy and safety of tramadol versus morphine for moderate and severe postoperative pain with special regard to respiratory depression. Anesth Analg 1992;74:510-4.

15. Raffa RB, Friderichs E, Reimann W, Shank RP, Codd EE, Vaught JL. Opioid and nonopioid components independently contribute to the mechanism of action of tramadol, an 'atypical' opioid analgesic. J Pharmacol Exp Ther 1992;260:275-85.

16. Roth SH. Efficacy and safety of tramadol $\mathrm{HCl}$ in breakthrough musculoskeletal pain attributed to osteoarthritis. J Rheumatol 1998;25:1358-63.

17. Gardner JS, Blough D, Drinkard CR, et al. Tramadol and seizures: A surveillance study in a managed care population. Pharmacotherapy 2000;20:1423-31.

18. Gasse C, Derby L, Vasilakis-Scaramozza C, Jick H. Incidence of first-time idiopathic seizures in users of tramadol. Pharmacotherapy 2000;20:629-34.

19. Jick H, Derby LE, Vasilakis C, Fife D. The risk of seizures associated with tramadol. Pharmacotherapy 1998;18:607-11.

20. Gillman PK. Monoamine oxidase inhibitors, opioid analgesics and serotonin toxicity. Br J Anaesth 2005;95:434-41.

21. Dalgin P; for the TPS-OA study group. Comparison of tramadol and ibuprofen for the chronic pain of osteoarthritis. Arthritis Rheum 1997;40(Suppl 9):S86. (Abst)

22. Pavelka K. Treatment of pain in osteoarthritis. Eur J Pain 2000;4(Suppl A):23-30.

23. Adler L, McDonald C, O'Brien C, Wilson M. A comparison of once-daily tramadol with normal release tramadol in the treatment of pain in osteoarthritis. J Rheumatol 2002;29:2196-9.

24. Simon L, Lipman A, Jacox A. Guideline for the Management of Pain in Osteoarthritis, Rheumatoid Arthritis and Juvenile Chronic Arthritis, 2nd ed. Glenview: American Pain Society, 2002.

25. Schnitzer TJ, Gray WL, Paster RZ, Kamin M. Efficacy of tramadol in treatment of chronic low back pain. J Rheumatol $2000 ; 27: 772-8$ 
26. Harati Y, Gooch C, Swenson M, et al. Double-blind randomized trial of tramadol for the treatment of the pain of diabetic neuropathy. Neurology 1998;50:1842-6.

27. Harati Y, Gooch C, Swenson M, et al. Maintenance of the longterm effectiveness of tramadol in treatment of the pain of diabetic neuropathy. J Diabetes Complications 2000;14:65-70.

28. Sindrup SH, Andersen G, Madsen C, Smith T, Brøsen K, Jensen TS. Tramadol relieves pain and allodynia in polyneuropathy: A randomised, double-blind, controlled trial. Pain 1999;83:85-90.

29. Russell IJ, Kamin M, Sager DS, et al. Efficacy of tramadol in treatment of pain in fibromyalgia. Arthritis Rheum 1997;40(Suppl):S521.

30. Keup W. Mißbrauchsmuster bei Abhängigkeit von Alkohol, Medikamenten und Drogen: Frühwarnsystem-daten für die Bundesrepublik Deutschland 1976-1990. Lambertus: Freiburg im Breisgau, 1993.

31. Preston KL, Jasinski DR, Testa M. Abuse potential and pharmacological comparison of tramadol and morphine. Drug Alcohol Depend 1991;27:7-17.

32. Cicero TJ, Adams EH, Geller A, et al. A postmarketing surveillance program to monitor Ultram (tramadol hydrochloride) abuse in the United States. Drug Alcohol Depend 1999;57:7-22.

33. Knisely JS, Campbell ED, Dawson KS, Schnoll SH. Tramadol postmarketing surveillance in health care professionals. Drug Alcohol Depend 2002;68:15-22.

34. WHO Expert Committee on Drug Dependence. Thirty-fourth report. <http://whqlibdoc.who.int/trs/WHO_TRS_942_eng.pdf> (Version current March 26, 2008).

35. Richter W, Barth H, Flohé L, Giertz H. Clinical investigation on the development of dependence during oral therapy with tramadol. Arzneimittelforschung 1985;35:1742-4.

36. Osipova NA, Novikov GA, Beresnev VA, Loseva NA. Analgesic effect of tramadol in cancer patients with chronic pain: A comparison with prolonged-action morphine sulfate. Curr Ther Res 1991;50:812-21.

37. Chrubasik J, Buzina M, Schulte-Mönting J, Atanassoff P, Alon E. Intravenous tramadol for post-operative pain - comparison of intermittent dose regimens with and without maintenance infusion. Eur J Anaesthesiol 1992;9:23-8.

38. Wilder-Smith $\mathrm{CH}$, Bettiga $\mathrm{A}$. The analgesic tramadol has minimal effect on gastrointestinal motor function. Br J Clin Pharmacol 1997;43:71-5

39. Janssen-Ortho Inc. Product Monograph. Tramacet. $<$ http://www.janssen-ortho.com/JOI/pdf_files/tramacet_E.pdf > (Version current at March 26, 2008).

40. Beaulieu AD, Peloso P, Bensen W, et al. A randomized, doubleblind, 8-week crossover study of once-daily controlled-release tramadol versus immediate-release tramadol taken as needed for chronic noncancer pain. Clin Ther 2007;29:49-60.

41. Beaulieu A, Callaghan D, O'Mahony W, et al. A randomized, double-blind, crossover comparison of the efficacy and safety of oral controlled release tramadol with placebo in patients with painful osteoarthritis. Pain Res Manage 2006;11:108. (Abst)

42. Symposium on Population Studies in Relation to Chronic Rheumatic Diseases, Rome, 1961. The Epidemiology of Chronic Rheumatism, Volume 2: Atlas of Standard Radiographs of Arthritis. Philadelphia: FA Davis, 1963.
43. Bellamy N, Buchanan WW, Goldsmith CH, Campbell J, Stitt LW. Validation study of WOMAC: A health status instrument for measuring clinically important patient relevant outcomes to antirheumatic drug therapy in patients with osteoarthritis of the hip or knee. J Rheumatol 1988;15:1833-40.

44. Bellamy N. Pain assessment in osteoarthritis: Experience with the WOMAC osteoarthritis index. Semin Arthritis Rheum 1989;18(Suppl 2):14-7.

45. Bellamy N, Carette S, Ford PM, et al. Osteoarthritis antirheumatic drug trials. III. Setting the delta for clinical trials - results of a consensus development (Delphi) exercise. J Rheumatol 1992;19:451-7.

46. Holman GH. Chronic nonmalignant pain. Clin Geriatr 1997;5:214,27-9,32-5,38,41.

47. Cepeda MS, Camargo F, Zea C, Valencia L. Tramadol for osteoarthritis: A systematic review and meta-analysis. J Rheumatol 2007;34:543-55.

48. Thorne C, Beaulieu AD, Callaghan DJ, et al. A randomized, double-blind, crossover comparison of the efficacy and safety of oral controlled-release tramadol and placebo in patients with painful osteoarthritis. Pain Res Manage 2008;13:93-102.

49. Pavelka K, Peliskova Z, Stehlikova H, Ratcliffe S, Repas C. Intraindividual differences in pain relief and functional improvement in osteoarthritis with diclofenac or tramadol. Clin Drug Investig 1998;16:421-9.

50. Sorge J, Stadler TH. Comparison of the analgesic efficacy and tolerability of tramadol $100 \mathrm{mg}$ sustained-release tablets and tramadol $50 \mathrm{mg}$ capsules for the treatment of chronic low back pain. Clin Drug Investig 1997;14:157-64.

51. Petrone D, Kamin M, Olson W. Slowing the titration rate of tramadol $\mathrm{HCl}$ reduces the incidence of discontinuation due to nausea and/or vomiting: a double-blind randomized trial. J Clin Pharm Ther 1999;24:115-23.

52. Ruoff GE. Slowing the initial titration rate of tramadol improves tolerability. Pharmacotherapy 1999;19:88-93.

53. Jensen EM, Ginsberg F. Tramadol versus dextropropoxyphene in the treatment of osteoarthritis. A short term double-blind study. Drug Invest 1994;8:211-8.

54. Rostom A, Dubé C, Jolicoeur E, Boucher M, Joyce J. Gastroduodenal ulcers associated with the use of non-steroidal antiinflammatory drugs: A systematic review of preventive pharmacological interventions. Ottawa: Canadian Coordinating Office for Health Technology Assessment, 2004.

55. Reig E. Tramadol in musculoskeletal pain - a survey. Clin Rheumatol 2002;21(Suppl 1):S9-11.

56. Roth SH, Fleischmann RM, Burch FX, et al. Around-the-clock, controlled-release oxycodone therapy for osteoarthritis-related pain: Placebo-controlled trial and long-term evaluation. Arch Intern Med 2000;160:853-60.

57. Caldwell JR, Hale ME, Boyd RE, et al. Treatment of osteoarthritis pain with controlled release oxycodone or fixed combination oxycodone plus acetaminophen added to nonsteroidal antiinflammatory drugs: A double blind, randomized, multicenter, placebo controlled trial. J Rheumatol 1999;26:862-9.

58. Markenson JA, Croft J, Zhang PG, Richards P. Treatment of persistent pain associated with osteoarthritis with controlled-release oxycodone tablets in a randomized controlled clinical trial. Clin J Pain 2005;21:524-35. 


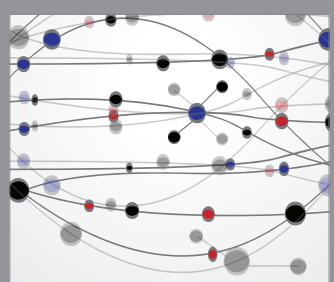

The Scientific World Journal
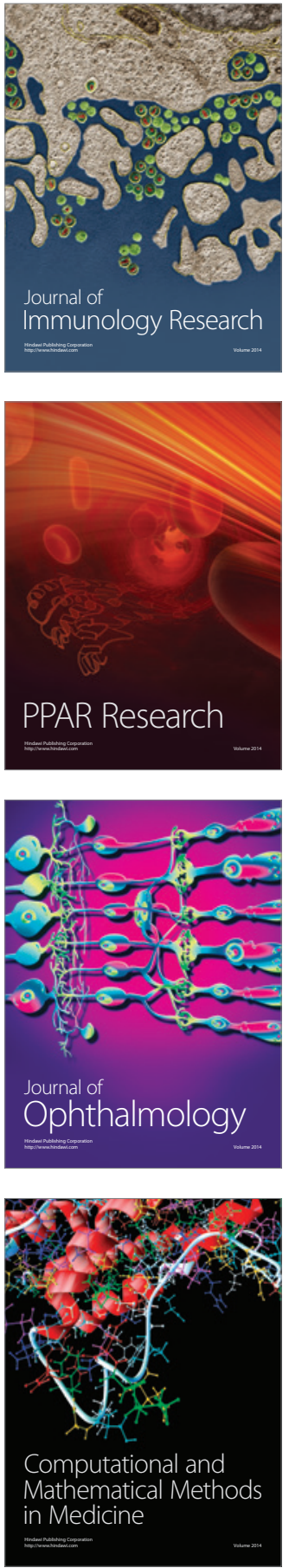

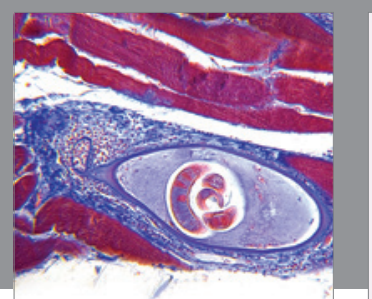

Gastroenterology Research and Practice

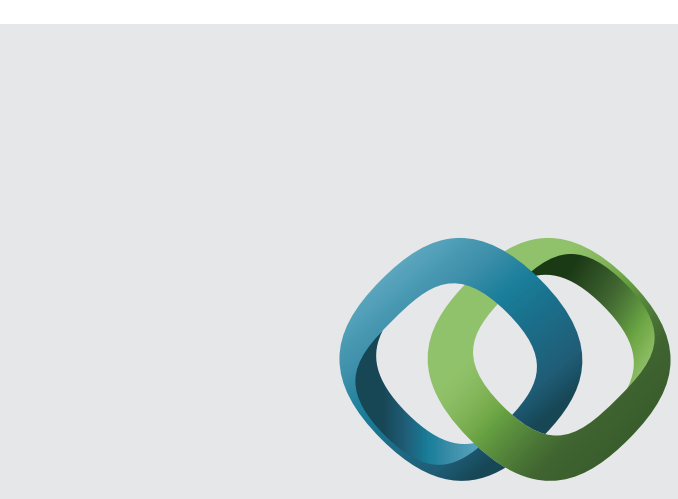

\section{Hindawi}

Submit your manuscripts at

http://www.hindawi.com
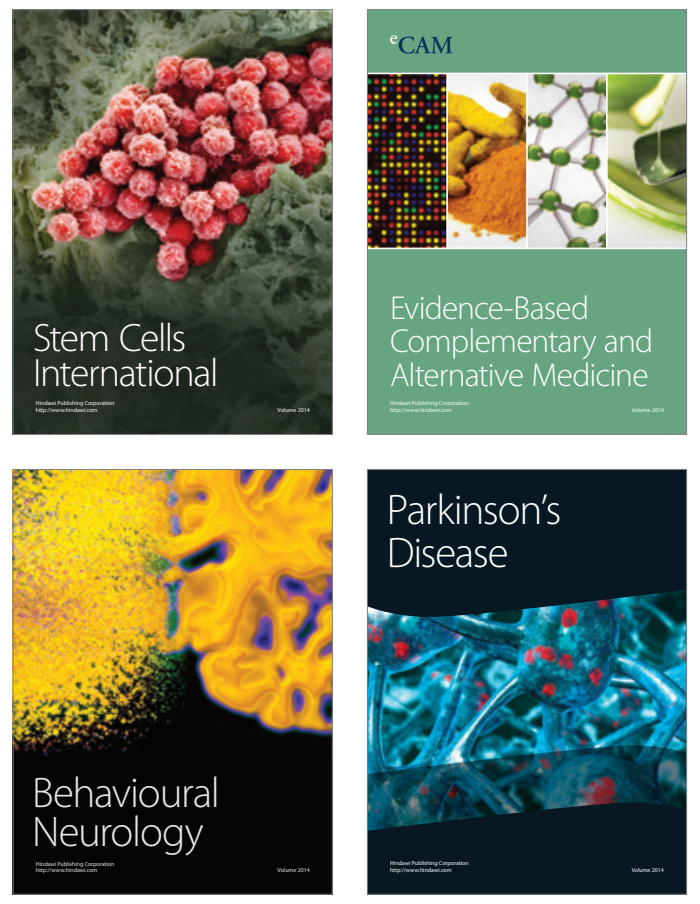
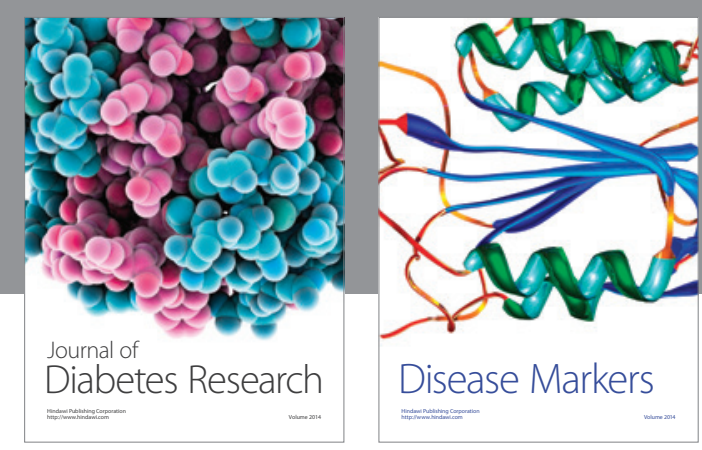

Disease Markers
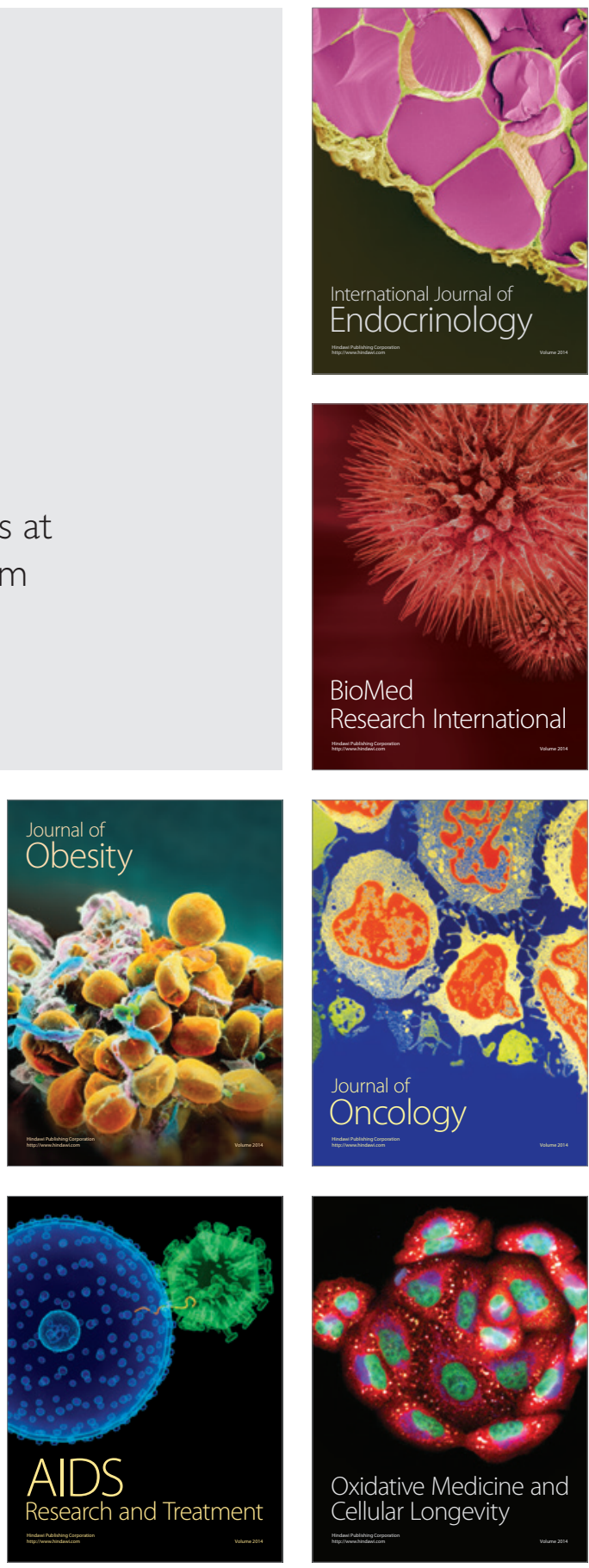